\title{
Foaming when the recycled water sludge is reused for FGD
}

\author{
Ziwei Li \\ North China Electric Power University, Baoding ,China \\ 1533191873@qq.com
}

Keywords: recycled water,sludge ,overflow,Bikerman experiment

\begin{abstract}
The utilization of water treatment plant for waste of calcium-containing sludge was analyzed, and as a desulfurization agent, desulfurization experiment was studied professionally. The analysis of causes of the foaming phenomenon simultaneous in desulfurization tower was also taken into account,proposing measures to deal with water sludge reusing for desulfurization system feasibility and foaming problems. Lay the foundation for the promotion of industrialization technology.
\end{abstract}

\section{The research background}

At present, China's urban water is treated by limestone mostly, this approach to water technology has already shaped ${ }^{[1]}$. Recycled water after lime treatment can reach the practical requirements, not only saves a lot of fresh water, and reduced waste pollution to the environment, it can be described as economic, social double harvest ${ }^{[2]}$. But at the same time, a large number of calcium-containing sludge has not been effectively utilized with the process. The sludge not only occupy a lot of land resources, but also created new environmental pollution, how to deal with the use of these calcium-containing sludge has become a new research topic.

According to the characteristic of calcium-containing sludge, using it for the desulfurization system can achieve the ideal effect of sulfur removal.In 1979, the EPA has published an article called "EPA Evaluation of Water Plant Lime Sludge in an Industrial Boiler FGD System at Rickenbacker AFB". Shouyangshan power plant in China,circulating water cooling system uses reclaimed water lime reusing process, the resulting sludge is used for flue gas desulfurization and gypsum production, almost "zero emissions." But it is important to truly realize the industrialization of the large-scale promotion, there still have a lot of problems need to overcome, to solve the desulfurization serous overflow is a critical problem. The scene photos of the overflow of a power plant desulfurization tower after blistering is shown as Figure 1

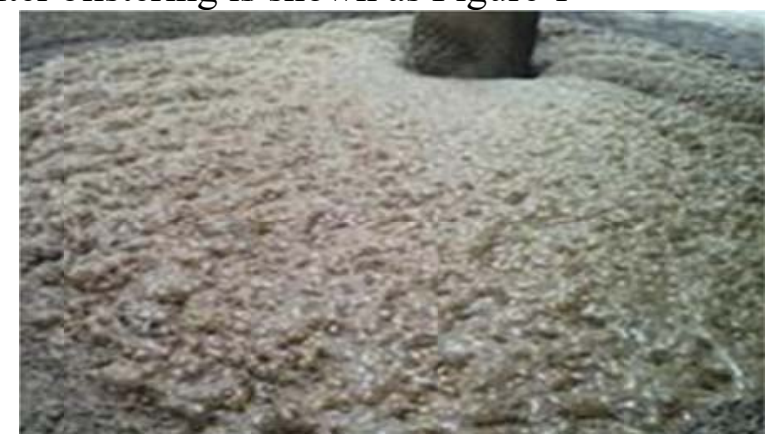

Fig1 seriflux foam after absorption tower overflowing

\section{The foaming phenomenon}

\section{1 foaming mechanism}

In the process of absorption tower operation, insoluble gas in the slurry will form a very thin layer of adsorption film, due to the effect of surface tension, adsorption film will gradually shrink into a ball and have a certain volume of air bubbles.Because of the difference between gas and liquid density, blister will soon rise to the surface and gather to create foam.In the normal operation 
of absorption tower,there still have mild foaming,liquid film be thinning in the process of foaming , until the break.But when other active substances exists in system, making the instability of the foaming weaken and increasing mechanical strength, to prevent further thinning of the liquid membrane, and then cause overflow ${ }^{[3]}$.

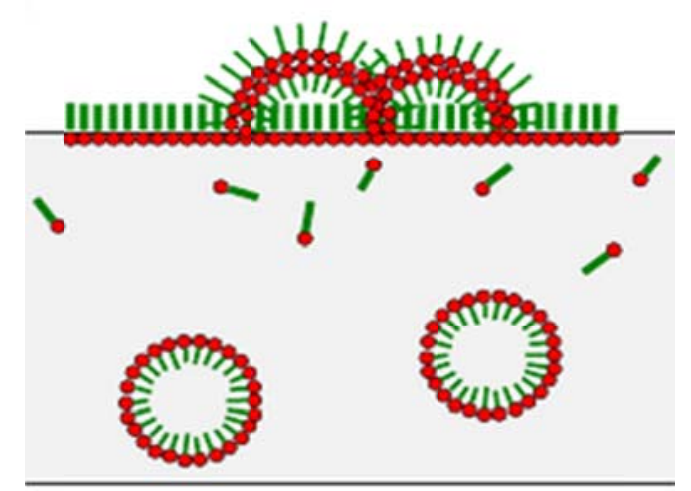

Fig2 Stable foam in surfactant containing systems

\section{2 blistering media}

Foaming medium include three ways:surfactant, macro-molecules and small, dispersed solid particles. Which is shown in the following Table 1.

\begin{tabular}{|c|l|}
\hline Medium & \multicolumn{1}{c|}{ Cause blistering } \\
\hline Macro-molecules & $\begin{array}{l}\text { They reduce the surface tension of the bubble and decrease } \\
\text { required energy when foam gathering and expanding }\end{array}$ \\
\hline Surfactants & $\begin{array}{l}\text { Surfactants make foam thin-wall ability enhance to resist } \\
\text { local thinning, so that is not easy to break; they also make } \\
\text { thin-walled increase in viscosity and generating electrostatic } \\
\text { repulsion between the two thin-walled bubble wen } \\
\text { contacting, so that there is a time to increase. }\end{array}$ \\
\hline Solid particles & $\begin{array}{l}\text { Hydrophobic and electrostatic interactions of the solid } \\
\text { particles adhere to the bubbles' surface resulted to the bubble } \\
\text { size-reduction,water loss, and to enhance the strength of the } \\
\text { thin-walled bubble, resulting in the presence of prolonged }\end{array}$ \\
\hline
\end{tabular}

Table 1 Foaming media effects

Moreover, the buffer plays the role of activators.limestone, gypsum and fly ash as adhesive particles, macromolecular protein produced by a microorganism, will promote the generation of bubbles. Oil and hydrophobic particles can also have side effects, such as promoting proteins produced by microorganisms and gypsum fade.

\section{Experimental Inquiry}

\subsection{Component Analysis}

After experimental determination, the main ingredients in the sludge are calcium hydroxide and calcium carbonate.Because of the addition of a coagulant, the sludge contains a small amount of Aluminum oxide;Moreover, sludge also contains $\mathrm{Pb}, \mathrm{Hg}$, As and other heavy metal ions and a spot of macro molecule, such as proteins, etc.

The main component of the sludge in the Table 2

\begin{tabular}{lllll}
\hline Ingredient & $\mathrm{CaCO}_{3}$ & $\mathrm{MgCO}_{3}$ & $\mathrm{Al}_{2} \mathrm{O}_{3}$ & $\mathrm{SiO}_{2}$ \\
\hline Content(\%) & 75.45 & 17.30 & 5.03 & 2.22 \\
\hline
\end{tabular}

Table2 Mud of a power plant component composition 


\subsection{Experimental Method}

Through analysis for reasons about blistering, we hypothesized that the sludge reused for desulfurization system may cause the absorption tower overflow, containing the following aspects:flocculant, heavy metals, organic compounds and so on.

This experiment adopts the Bikerman method ${ }^{[4]}$, the different factors of preliminary screening sludge composition analysis for sludge;By surface tension measurement to determine the foaming mechanism and the concentration dependence of the parameter.The illustration of test procedures as shown in Figure 3.

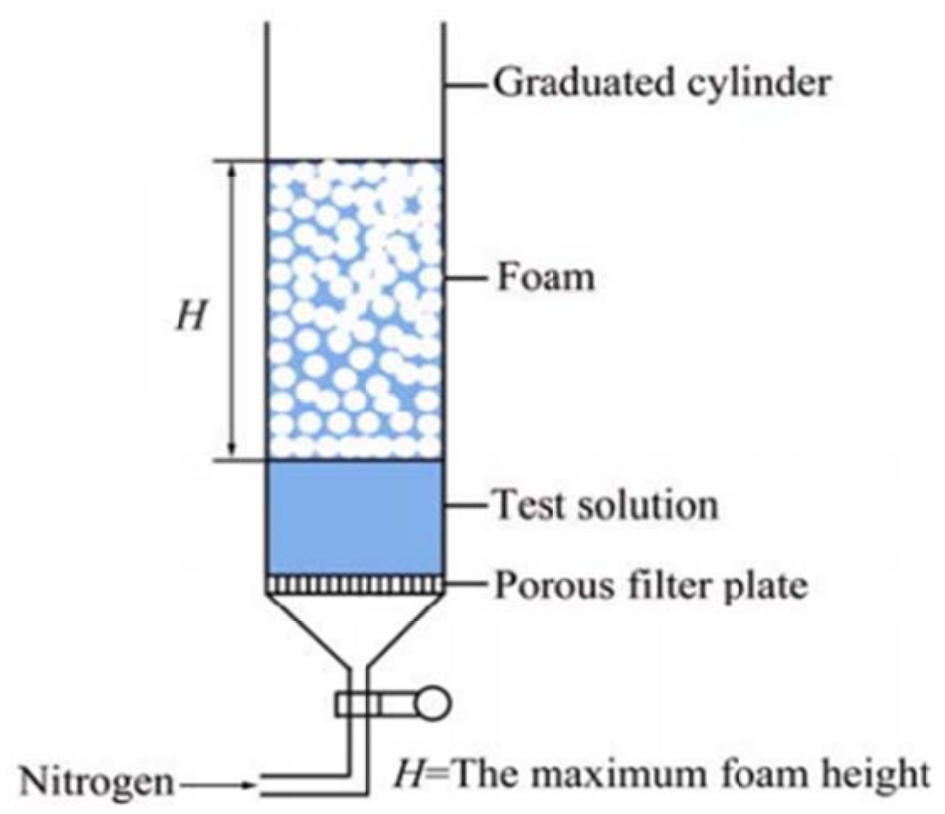

Fig3 Illustration of test procedures

Experimental procedure is as follows:

(1)Make use of $0.07 \mathrm{~m}$ internal diameter glass cylinder, a porous disc in the bottom . Bubbles from the porous disc by the bubbling of nitrogen gas to obtain.At room temperature, blistering of $0.1 \mathrm{~L}$ different solutions analyzed.

(2) 2 parts collected from the scene to the desulfurization solution (pregnant solution) will be numbered A, B and processed in accordance with the following two methods:

A:Direct filtration, the filtrate was collected to make foaming performance measured.

B:Take $100 \mathrm{~mL}$ desulfurization solution, $5.0 \mathrm{~g}$ activated carbon was added slowly with stirring $2.0 \mathrm{~h}$ at $40{ }^{\circ} \mathrm{C}$.After filtering, the filtrate was collected to make foaming performance measured.

\subsection{The result analysis}

By contrast, found that sludge which is rich in active substances (organic matter,heavy metal,etc.)can produce foaming phenomenon.Among them, inorganic compounds, especially the high magnesium content of the sludge occurs more severe blistering. The reason can be considered as magnesium oxide with the $\mathrm{SO}_{4}^{2-}$ reaction would produce large amounts of bubbles, and will affect the crystallization and dehydration. Comprehensive comparative analysis, water sludge and limestone powder purchased have a considerable desulfurization efficiency, but due to the variety of composition of mixed, causing severe blistering in the tower.

\section{Conclusion}

According to characteristics of the calcium-containing sludge derived from water treatment ,In this paper, the absorption tower overflow problem to be researched The experimental results show 
that as the desulfurization absorbent is a relatively appropriate utilization method, making the best re-use as a secondary resource.But compared with the traditional desulfurizer, blistering is more serious when sludge used in desulfurization system . In order to realize large-scale industrial applications, there need to find the effective solutions.

\section{Reference}

[1]Nural Kuyucak,Selecting Suitable Methods For Treating Mining Effluent, Golder Associates Ltd.,32 Steacie Drive, Kanata, Ontario,Canada K2K 2A9

[2]Qunkui Wang, Discussion lime advanced treatment of water in the city,Shandong Industrial Technology, 2015.

[3]Wenli Mao,Hui Li, Biao Chen,Coal-fired power generating units desulfurization tower slurry foaming problem analysis and countermeasures, Zhejiang Electric Power, 2014.

[4] Brian Brun Hansen,Crystallization of Gypsum and Prevention of Foaming in Wet Flue Gas Desulphurisation (FGD) Plants,J\&R Frydenberg A/S, Copenhagen, Denmark(2009) 